\title{
PENGARUH PELATIHAN ENTREPRENEURSHIP TERHADAP PENINGKATAN EKONOMI JEMAAT GKII SYALOM MAKASSAR
}

\author{
Herman Rura, Hengki Wijaya
}

\begin{abstract}
Abstrak
Ide penulisan judul penelitian ini munculnya dari pengalaman penulis saat melakukan kuliah kerja lapangan di GKII Syalom Makassar. Pada saat itu penulis terlibat langsung dalam pelatihan entrepreneurship sebagai salah satu program kerja seksi professional di jemaat GKII Syalom Makassar. Bagi penulis program tersebut adalah suatu bentuk terobosan baru yang jarang ditemukan dalam gereja-gereja secara umum. Program tersebut selaras dengan seruan PGI untuk memberdayaan ekonomi jemaat yaitu pelayanan diakonia secara transformatif. Dari pengamatan penulis, nampaknya program jemaat tersebut belum berjalan secara optimal seperti yang diharapkan. Untuk menjawab pertanyaan tersebut di atas, maka penulis meneliti, (1) bentuk-bentuk usaha entrepreneurship apa saja yang telah dilakukan oleh warga jemaat, dan (2) untuk mengetahui taraf perekonomian sebelum dan sesudah menggeluti usaha tersebut. Konsep entrepreneurship digali melalui studi literatur dengan metode deskripsi analitis serta berdasarkan teks Alkitab. Kemudian membandingkannya dengan praktik entrepreneurship yang dilakukan secara nyata di dalam jemaat. Data yang telah dikumpulkan dari populasi atau sampel, selanjutnya dianalisis agar dapat diartikan. Hasil penelitian menemukan usaha-usaha yang sedang dilakukan adalah: warung kelontong, peternakan ayam, kerajinan tangan, usaha transportasi, usaha bengkel las serta usaha kuliner. Berdasarkan analisis indikator-indikator yang memengaruhi peningkatan pendapatan, peningkatan Quality of Life, peningkatan kepuasan kerja, serta peningkatan kesejahteraan, maka penulis menyimpulkan bahwa secara keseluruhan kegiatan entrepreneurship di jemaat GKII Syalom Makassar belum berhasil meningkatkan ekonomi jemaat secara signifikan, karena masih berada dalam tahap pengembangan.
\end{abstract}

Kata-Kata Kunci: Entrepreneurship, Ekonomi, Gereja, Jemaat, GKII Syalom Makassar

\section{Pendahuluan}

\section{Latar Belakang Masalah}

Munculnya ide pemilihan judul skripsi ini, terdorong oleh pengalaman penulis saat melakukan kuliah kerja lapangan di GKII Syalom Makassar. Pada saat itu penulis terlibat langsung dalam pelatihan entrepreneurship yaitu salah satu program kerja jemaat yang bagi penulis adalah suatu bentuk terobosan baru yang jarang ditemukan dalam gerejagereja secara umum.

Dewasa ini memang penelitian tentang entrepreneuship secara umum sudah banyak dilakukan, namun studi tentang hubungan antara teologi dengan entrepreneurship dan kewirausahaan termasuk bidang yang baru. Terlebih hubungan antara entrepreneur dengan 
gereja yang masih menimbulkan paradox seperti ungkapan Dekker. ${ }^{1}$ Praktik entrepreneurship sebenarnya telah berlangsung dalam kehidupan berjemaat kita. Gereja Masehi Injili di Timor (GMIT) Kupang dan Gereja Toraja khususnya klasis Makassar telah mengembangkan kewirausahaan di bidang koperasi. ${ }^{2}$ Demikian juga dengan pengembangan ekonomi yang diselenggarakan oleh Gereja Kristen Protestan Bali (GKPB) yang merintis program pembuatan pupuk sampah organik rumah tangga. ${ }^{3}$

Namun sampai saat ini kegiatan entrepreneurship dalam gereja masih menimbulkan pro dan kontra yang berkepanjangan. Ada kalangan yang menganggap: gereja mengajarkan solidaritas sedang bisnis mengharuskan persaingan. ${ }^{4}$ Masing-masing pihak mengajukan argumentasi teologis atas pendapatnya. Itulah sebabnya etika bisnis kristiani sampai sekarang tidak selesai dan tetap merupakan agenda yang belum terselesaikan. Bahkan ada orang yang sikapnya sangat negatif terhadap pekerjaan. ${ }^{5}$ Golongan yang tidak setuju, memberikan alasan dengan peristiwa saat Yesus mengusir para pedagang di Bait Allah di Lukas 19:45-46 dengan perkataan "... Ada tertulis: Rumah$\mathrm{Ku}$ adalah rumah doa. Tetapi kamu menjadikannya sarang penyamun”. Sehingga kelompok yang kontra tersebut berkesimpulan bahwa dunia usaha tidak boleh dimasukkan kedalam gereja. ${ }^{6}$ Bahkan secara tradisional, teks dari Matius 5:3 sering dipakai untuk "melegalkan" kemiskinan di kalangan jemaat kristiani, serta untuk menghibur mereka yang miskin di dunia karena mereka akan kaya dan selamat di Surga. ${ }^{7}$ Namun perlu dipahami bahwa Yesus bukannya tidak setuju dengan perdagangan tetapi Yesus menghukum orang yang menggunakan gereja dan Injil demi keuntungan diri pribadi. ${ }^{8}$

Sedang golongan yang pro memakai argumentasi dari Amsal 21:5a “... orang rajin semata-mata mendatangkan kelimpahan". Tuhan juga berjanji bahwa jika orang-orang yang dipanggil dalam nama-Nya mematuhi hukum dan perintah-Nya, maka ia akan memberkati dengan kemakmuran yang melebihi setiap bangsa di bumi (Ulangan 28:8-13). ${ }^{9}$

Kritik Yahya Wijaya dalam bukunya yang berjudul "Kesalehan Pasar" tentang sikap gereja yang seringkali dipahami sekadar bersifat pragmatis; gereja membutuhkan kalangan bisnis hanya untuk mencukupi kebutuhan pendanaan; sedang pelaku bisnis membutuhkan gereja untuk kebutuhan ritual sebagai penyegaran saat memotivasi para pekerja agar semakin produktif. ${ }^{10}$ Adalah suatu ironi jika gereja berbicara tentang

\footnotetext{
${ }^{1}$ Peter Dekker. "Entrepreneurship and the Relation with Mission in the Church of Indonesia" Jurnal Jaffray [Online], Volume 18 Number 2 (27 October 2020), 177. https://ojs.sttjaffray.ac.id/JJV71/article/view/437.

${ }^{2}$ Purnama Pasande dan Ezra Tari, "Peran Gereja Dalam Mengembangkan Program Kewirausahaan Dalam Menghadapi Era Digital,”Visio Dei 1, no. 1 (Juli 2019): 47, diakses 13 Juli 2019, http://jurnal.sttstarslub.ac.id/index.php/js/article/view/6.

${ }^{3}$ Made Gunaraksawati Mastra-Ten Veen, Teologi Kewirausahaan (Yogyakarta: Taman Pustaka Kristen, 2009), 222-223.

${ }^{4}$ Yahya Wijaya, Kesalehan Pasar - Kajian Teologis Terhadap Isu-isu Ekonomi dan Bisnis di Indonedia, 1 ed. (Jakarta: Grafika Kreasindo, 2010), 2-3.

${ }^{5}$ John Stott, Isu-isu Global Menentang Kepemimpinan Kristiani, 1 ed. (Jakarta: Yayasan Komunikasi Bina Kasih, 2012), 213.

${ }^{6}$ Julianto Simon, “Kewirausahaan Jemaat: Sebuah Alternatif Berteologi,” Waskita 3, no. 1 (2016): 152, http://ejournal.uksw.edu/waskita/article/view/1309.

${ }^{7}$ F. Nanuru, Ricardo, dan Lomas Beatris Limpong, "Pandangan Gereja Masehi Injili di Halmahera (GMIH) Wilayah Pelayanan Tobelo Terhadap Dunia Bisnis," Jurnal Uniera 3, no. 1 (2014): 60, diakses 01 Mei 2019, https://osf.io/preprints/hz8cq/.

${ }^{8}$ Donald C. Stamps, Alkitab Penuntun Hidup Berkelimpahan, 1 ed. (Malang: Gandum Mas, 1994), 1678.

${ }^{9}$ Larry Burkett, Bisnis Menurut Alkitab, 1 ed. (Yogyakarta: Yayasan ANDI, 1997), 14.

${ }^{10}$ Yahya Wijaya, Kesalehan Pasar - Kajian Teologis Terhadap Isu-isu Ekonomi dan Bisnis di Indonedia, 1 ed. (Jakarta: Grafika Kreasindo, 2010), 1-2.
} 
pemberdayaan ekonomi jemaat, tetapi nyatanya gereja sebagai lembaga tidak pernah melakukan investasi untuk berkarya dan mengkaryakan anggotanya dalam dunia wirausaha/bisnis. Padahal gereja memiliki kemampuan sumberdaya dan dana untuk berkecimpung dalam dunia tersebut. ${ }^{11}$

Sebagai bentuk kepedulian ekonomi tersebut, maka telah dibahas dalam satu program kerja Sidang Raya PGI (Persekutuan Gereja-Gereja di Indonesia) yang XVI di Gunung Sitoli, Pulau Nias, Sumatera Utara, pada tahun 2014 lalu. Judul pokok bahasannya "Pemberdayaan Ekonomi Jemaat Tak Lagi Bicara Teori" yang di jabarkan kedalam tiga sub pokok bahasan yaitu: ${ }^{12}$ Pertama, upaya pemberdayaan ekonomi jemaat adalah dalam rangka mengembangkan ekonomi warga gereja. Kedua, tujuan utama dari pemberdayaan ekonomi jemaat agar dengan inisiatif bersama, maka usaha-usaha untuk mengembangkan ekonomi warga jemaat baik secara pribadi maupun keluarga dapat bergulir. Ketiga, pemberdayaan ekonomi jemaat merupakan bagian pelayanan diakonia gereja secara transformatif.

Sebagai respons dari keputusan PGI tersebut di atas, maka beberapa gereja telah melakukan wirausaha di tingkat jemaat seperti Gereja Kristen Protentan Bali (GKPB) yang melakukan bisnis memakai pendekatan berimbang yang berbasis pada diakonia reformatif, yaitu pendekatan diakonia yang mementingkan karya penguatan kapasitas masyarakat yang didampingi. Program tersebut lebih dikenal dengan istilah "bantuan untuk memberi kail dan bukan langsung memberikan ikan". ${ }^{13}$ Karena penyelesaian jangka panjang untuk kemiskinan individu bukanlah fungsi peningkatan pembayaran atau penambahan program lain untuk mengundang para tunawisma ke tempat penampungan - melainkan membuka wawasan untuk bekerja. ${ }^{14}$

Demikian juga dengan gereja Kristen Jawa (GKJ) yang mengalami percepatan kesadaran untuk bangkit dari keterpurukan akibat kebijakan Gereja Belanda yang menghentikan semua bantuan keuangan secara bertahap sejak tahun 1980-1990-an. Peristiwa ini menumbuhkan semangat kemandirian untuk melakukan bisnis properti, menanam modal di Koperasi dan menanam investasi jangka pendek di Agrowisata. Modal ini sesungguhnya adalah "hati yang bertanggung jawab atas kepercayaan yang Tuhan berikan melalui karya kewirausahaan. ${ }^{15}$

Gereja Masehi Injili di Minahasa (GMIM) terpanggil untuk mendirikan suatu organisasi yang diberi nama Pusat Pembinaan Warga Gereja (PPWG) sebagai tanggung jawab terhadap masalah-masalah sosial yang ada di sekitar daerah pelayanannya, khususnya yang berdomisili di Kaaten Tomohon. Dengan membuka Balai Kerja dan Latihan Ketrampilan (BKLK) untuk latihan kerja bidang konsultan, bangunan, Mebel, elektronik dan mekanik. Tetapi yang menjadi program andalan adalah pengolahan dan

${ }^{11}$ F. Nanuru, Ricardo, dan Lomas Beatris Limpong, "Pandangan Gereja Masehi Injili di Halmahera (GMIH) Wilayah Pelayanan Tobelo Terhadap Dunia Bisnis," Jurnal Uniera 3, no. 1 (2014): 53-54, diakses 01 Mei 2019, https://osf.io/preprints/hz8cq/.

${ }^{12}$ Vesto Proklamanto Magany, "SR XVI PGI: Pemberdayaan Ekonomi Jemaat Tak Lagi Bicara Teori” PGI, Oktober 2014, diakses 2 Mei 2019. https://pgi.or.id/sr-xvi-pgi-pemberdayaan-ekonomi-jemaattak-lagi-bicara-teori/.

${ }^{13}$ Made Gunaraksawati Mastra-Ten Veen, Teologi Kewirausahaan (Yogyakarta: Taman Pustaka Kristen, 2009), 111.

${ }^{14}$ David W. Hall dan Matthew D. Burton, Calvin dan Perdagangan, 1 ed. (Surabaya: Momentum, 2015), 194-195.

${ }^{15}$ Julianto Simon, "Kewirausahaan Jemaat: Sebuah Alternatif Berteologi," Waskita 3, no. 1 (2016): 165-171, http://ejournal.uksw.edu/waskita/article/view/1309 
pemanfaatan kayu kelapa. Program latihan kerja tersebut telah berhasil mendidik banyak tenaga kerja yang berasal dari anak-anak putus sekolah, baik tingkat SMP maupun SMA. ${ }^{16}$

Dalam rangka menjawab pergumulan ekonomi jemaat tersebut, maka GKII Syalom Makassar telah menetapkan program kerja yang dibidangi oleh Seksi Profesional sejak tahun 2017 dan ditetapkan dalam keputusan rapat kerja pengurus GKII Jemaat Syalom Makassar. ${ }^{17}$ Dengan penetapan program tersebut menunjukkan kepedulian bahwa lembaga keagamaan tidak hanya bergerak dalam bidang spiritual, namun lebih dari itu gereja ikut bertanggung jawab dalam meningkatkan kesejahteraan ekonomi warganya.

Berdasarkan hasil observasi dan wawancara yang telah dilakukan penulis terhadap beberapa anggota jemaat, penulis melihat proses pelatihan entrepreneurship yang dilakukan di jemaat GKII Syalom telah berhasil membuka pola pikir dari jemaat, namun belum berjalan secara optimal seperti yang diharapkan. Terdapat beberapa masalah yang menghambat kelancaran penerapan. Untuk dapat menjalankan perannya dalam mensejahterakan warga jemaat, melalui pembinaan/pelatihan yang dikenal dengan istilah pelayanan diakonia reformatif ${ }^{18}$, maka GKII Syalom Makassar harus mampu memberdayakan semua potensi yang ada dalam jemaat. Mendorong para pemuda-pemudi untuk berani melakukan usaha sendiri ketimbang hanya menunggu kesempatan menjadi pekerja. Serta membina jemaat untuk menjadi pelaku bisnis yang sejalan dengan etika Kristen. Dapat menciptakan sebuah produk yang bermanfaat sebagaimana yang dipaparkan Wijaya dan kawan-kawan. ${ }^{19}$ Persoalan dan tantangan sebagai jemaat adalah: apakah kita telah mejalankan bisnis itu dengan cara-cara yang sesuai dengan etika Kristen, yang tidak manipulatif dan tidak mengorbankan konsumen. ${ }^{20}$

\section{Pokok Masalah}

Berdasarkan latar belakang masalah yang telah diuraikan di atas, maka yang menjadi pokok masalah dalam penulisan skripsi ini adalah: Pertama, apa saja bentukbentuk usaha entrepreneurship yang dilakukan oleh jemaat? Kedua, apakah pengaruh pelatihan entrepreneurship terhadap peningkatan ekonomi warga jemaat GKII Syalom Makassar.

\section{Tujuan Penelitian}

Adapun tujuan penelitian yang ingin dicapai dalam penulisan skripsi ini adalah untuk menjelaskan pengaruh entrepreneurship terhadap ekonomi jemaat GKII Syalom Makassar. Yaitu bentuk-bentuk usaha entrepreneurship apa saja yang telah dilakukan oleh warga jemaat, serta untuk mengetahui taraf perekonomian sebelum dan sesudah menggeluti usaha tersebut.

\section{Manfaat Penelitian}

Melalui penulisan skripsi ini, maka penulis akan menjelaskan beberapa manfaat seperti: pertama, sebagai bahan evaluasi program kerja di jemaat GKII Syalom Makassar, agar dapat ditingkatkan di masa-masa mendatang. Kedua, sebagai bahan acuan bagi para pemimpin gereja dalam meningkatkan ekonomi warga jemaatnya, melalui program

\footnotetext{
${ }^{16}$ Grace Sumbung dkk., "Peran Gereja Dalam Peningkatan Ekonomi Masyarakat Di Tomohon Sulawesi Utara,” Wacana 15, no. 4 (2012): 10-12, diakses 01 Juli 2019, https://wacana.ub.ac.id/index.php/wacana/article/view/264

${ }^{17}$ GKII Syalom, Keputusan Rapat Kerja Pengurus (Makassar, 2018)

${ }^{18}$ Yosep P. Widyatmadja, Diakonia Sebagai Misi Gereja (Yogyakarta: Kanisius, 2009), 113.

${ }^{19}$ Wijaya, Rouw, dan Kadir, 1.

${ }^{20}$ Victor P.H. Nikijuluw, Kitab Amos: Tanggung Jawab Orang Kristen dalam Mengatasi Masalah Sosial, Budaya, Ekonomi dan Politik (Bogor: Literatur Perkantas, 2016), 21.
} 
diakonia secara transformatif. Ketiga, untuk memenuhi salah satu persyaratan akademik bagi penulis untuk memperoleh gelar Sarjana Teologi pada Sekolah Tinggi Filsafat Jaffray Makassar. Keempat, sebagai bahan masukan bagi mahasiswa yang akan melaksanakan pelayanan dan penelitian-penelitian selanjutnya.

\section{Metode Penelitian}

Penulisan skripsi ini menggunakan metode penelitian kuantitatif, yaitu menggunakan simbol-simbol angka terhadap keadaan suatu sampel sehingga menghasilkan suatu kesimpulan yang dapat berlaku pada suatu populasi. ${ }^{21}$

Untuk mendapatkan penegasan, maka teknik pengumpulan data menggunakan metode observasi, angket (kuisioner) dan wawancara. ${ }^{22}$

Sedang konsep entrepreneurship di jemaat digali berdasarkan teks Alkitab dan study kepustakaan yang meliputi buku-buku dan jurnal-jurnal yang berkaitan dengan judul penelitian ini. Selanjut penulis mencermati materi pelatihan dan penerapan dari hasil pelatihan entrepreneurship itu sejauh mana memengaruhi persoalan konkrit ekonomi jemaat GKII Syalom Makassar.

\section{Batasan Penelitian}

Untuk menghindari adanya penyimpangan, dan agar penelitian ini lebih terarah serta tetap berfokus pada inti permasalahan untuk memudahkan dalam pembahasan, maka penulis membatasi ruang lingkup kajian hanya kepada warga jemaat GKII Syalom Makassar yang telah mengikuti pelatihan entrepreneurship kemudian melakukan usaha wirausaha.

\section{Sistematika Penulisan}

Penulisan dalam skripsi ini terdiri dari lima bab, yang dikelompokkan menjadi beberapa sub bab dengan sistematika penyusunan sebagai berikut:

Pada bab pertama, berisikan Latar Belakang masalah, Pokok Masalah, Tujuan penelitian, Manfaat penelitian, Metode penelitian, Batasan Penelitian dan Sistematika Penulisan.

Bab kedua, terdiri dari kajian teoritis tentang hakikat entrepreneurship dan hakikat ekonomi serta dasar teologinya. Pelatihan entrepreneurship, bentuk-bentuk usaha entrepreneurship serta indikator-indikator peningkatan ekonomi.

Pada bab ketiga tentang gambaran umum lokasi penelitian, usaha-usaha entrepreneurship yang sedang dilakukan di jemaat GKII Syalom Makassar, serta teknik pengumpulan dan teknik analisis data.

Sedang bab keempat, berisi profil subjet penelitian, pembahasan penelitian dan analisis hasil penelitian.

Bab kelima, terdiri dari kesimpulan berdasarkan hasil analisis data yang telah diuraikan pada bab-bab sebelumnya. Serta saran-saran bagi jemaat GKII Syalom Makassar dan peneliti-peneliti selanjutnya.

\section{Kesimpulan}

\footnotetext{
${ }^{21}$ Sumanto, Teori dan Aplikasi Metode Penelitian, 1 ed. (Jakarta: CAPS, 2014), 10.

${ }^{22}$ Hengki Wijaya, Metodologi Penelitian Pendidikan Teologi, 1 ed. (Makassar: Sekolah Tinggi Theologia Jaffray, 2016), 21-28; Serli dan Wijaya, 17; Hasmawaty, 55.
} 
Berdasarkan analisa angket serta wawancara dengan para responden, yaitu anggota jemaat GKII Syalom Makassar yang melakukan entrepreneurship, maka penulis berkesimpulan sebagai berikut:

Pertama, dari hasil analisa data maka dapat disimpulkan bawah pelatihan entrepreneurship telah memengaruhi pola pikir, semangat dan motivasi anggota jemaat GKII Syalom Makassar dalam melakukan wirausaha. Yaitu sekitar 20 orang (14\%) dari anggota jemaat yang hadir dalam pelatihan, dan 12 orang $(60 \%)$ dari anggota yang telah mendapat pelatihan yang telah aktif berusaha.

Kedua, ditinjau dari segi finansial maka keuntungan usaha entrepreneurship yang dilakukan oleh anggota jemaat GKII Syalom Makassar masih sangat minim, jadi mereka masih membutuhkan pendampingan dan bimbingan secara intensif oleh Seksi Profesional (lihat Lampiran 4.) Hal ini diperkuat dengan hasil wawancara dengan gembala jemaat yang menyatakan bahwa kas jemaat malahan mengalami penurunan dalam periode 2019 sehubungan dengan adanya perpindahan beberapa anggota warga jemaat ke kota lain. Sehingga pengaruh entrepreneurship belum dapat disandingkan dengan pendapatan gereja. $^{23}$

Ketiga, secara rata-rata usaha entrepreneurship di jemaat GKII Syalom Makassar adalah usaha yang baru sehingga masih dalam tahap pengembangan, sehinga malah semakin menyita waktu para responden untuk bertahan hidup.

Keempat, indikator peningkatan kesejahteraan juga belum menunjukkan gambaran yang positif, kecuali dalam hal ketenangan dalam bekerja dan kenyamanan dalam berinovasi.

Setelah mencermati semua indikator tersebut di atas, penulis menyimpulkan bahwa secara keseluruhan kegiatan entrepreneurship di jemaat GKII Syalom Makassar belum berhasil meningkatkan ekonomi jemaat secara finansial. Hal tersebut memberikan juga pelajaran baru bagi anggota jemaat untuk tidak hanya berfokus mencari keuntungan material, karena sisi rohani dan sosial juga penting. Hal ini nampak dalam indikator angket tentang "ketenangan dalam bekerja dan kebebasan dalam hal berinovasi" yang disetujui oleh semua responden.

\section{Saran-saran}

Setelah mencermati hasil-hasil angket, wawancara dan pengamatan secara langsung terhadap indikator-indikator pada anggota jemaat GKII Syalom Makassar yang melakukan pelatihan dan usaha entrepreneurship, maka penulis memberikan saran-saran dibawah ini:

Pertama, perlunya mengadakan pelatihan lanjutan yang mencakup cara-cara mengembangkan usaha, pengelolaan relasi bisnis serta penguatan permodalan.

Kedua, perlunya memperkuat pengajaran etika Kristen dari mimbar-mimbar gereja agar jemaat yang berprofesi sebagai entrepreneurship mempunyai dasar etika wirausaha yang lebih mementingkan pelayanan berkualitas ketimbang hanya mengutamakan keuntungan finansial belaka.

Ketiga, gereja perlu melakukan reformasi metode penginjilan dengan memakai model-model penginjilan kontekstual seperti praktik yang dilakukan oleh Peter Dekker. Artinya gereja perlu mencari warga potensial agar dipandu dan didampingi secara intensip dalam melakukan usaha. Dengan cara ini maka jalan masuk untuk mengabarkan injil akan terbuka secara luas.

\footnotetext{
${ }^{23}$ Simeon Sisatonis, Wawancara oleh Penulis, Makassar, 05 Agustus 2019
} 
Keempat, pada zaman milenial sekarang ini gereja perlu mereformasi dan mengubah metode pemberian diakonia tidak hanya bersifat karikatif tetapi dikombinasikan dengan cara-cara reformatif. Dengan cara ini pemberian ikan yang hanya bersifat sementara akan bergeser secara perlahan menjadi diakonia dengan model memberikan kail dibarengi dengan pelatihan keterampilan cara untuk memancing agar dapat menghasilkan ikan yang lebih banyak dan lebih segar.

\section{Kepustakaan}

Ali, Mohammad. Penelitian Kependidikan Prosedur dan Strategi. Bandung: Angkasa, 1985.

Ajeng, Diah, Partini Partini, dan Sri Peni. "Tantangan Sociopreneurs Yogyakarta di Era Comm 3.0." Profetik 11, no. 01 (2018): 12-25. Diakses 13 Mei 2019. http://ejournal.uin-suka.ac.id/isoshum/profetik/article/download/1420/1247.

Andriani, Meri, Yulina Ismida, dan Muhammad Thaib Hasan. "Perbaikan Produktivitas Usaha Bengkel Las Di Kecamatan Langsa Baro Melalui Aplikasi Ergonomi dan Kesehatan Keselamatan Kerja." Rekavasi 4, no. 2 (Agustus 2017): 15-22. Diakses 16 Juli 2019. https://docplayer.info/59318408-Perbaikan-produktivitas-usahabengkel-las-di-kecamatan-langsa-baro-melalui-aplikasi-ergonomi-dankeselamatan-kesehatan-kerja.html.

Ariati, Jati. "Subjective Well-Being (Kesejahteraan Subjektif) Dan Kepuasan Kerja Pada Staf Pengajar (Dosen) di Lingkungan Fakultas Psikologi Universitas Diponegoro." Jurnal Psikologi 8, no. 2 (2010): 117-123. Diakses 06 Juli 2019. https://ejournal.undip.ac.id/index.php/psikologi/article/view/2956.

Arwan, Adasiha, Mukhammad Kholid Mawardi, dan Aniesa Samira Bafadhal. "Pengaruh Kebijakan Pemerintah Terhadap Tingkat Kewirausahaan Di Indonesia." Jurnal Administrasi Bisnis 60, no. 3 (2018): 10-17. Diakses 09 Mei 2019. http://administrasibisnis.studentjournal.ub.ac.id/index.php/jab/article/download/252 $7 / 2917$.

Atmanti, Hastarini Dwi. "Kajian Teori Pemikiran Ekonomi Mazhab Klasik dan Relevansinya pada Perekonomian Indonesia." Jurnal Ekonomi \& Bisnis 2, no. 2 (September 2017): 511-524. Diakses 22 Juli 2019. http://jurnal.untagsby.ac.id/index.php/JEB17/article/view/1140.

Avin, Fadilla Helmi. "Kewirausahaan Di Perguruan Tinggi Dalam Perspektif Psikologi." Buletin Psikologi 17, no. 2 (2009): 66-89. Diakses 06 Agustus 2019. https://jurnal.ugm.ac.id/buletinpsikologi/article/view/11484.

Aziz, Fauzi. "Batik Diakui UNESCO.” Kementrian Perindustrian Indonesia. Diakses 08 April 2019. http://www.kemenperin.go.id/artikel/1961/batik-diakui-unesco.

Basuki, Imam. "Pemeliharaan Kinerja Angkutan Umum Perkotaan Menuju Transportasi Berkelanjutan.” Konteks 6, no.1 (Nopember 2012): 83-90. Diakses 26 Juli 2019. http://www.repository.trisakti.ac.id/webopac_usaktiana/index.php/home/detail/deta il_koleksi/0/PRO/judul/00000000000000006031/.

Bosrowi, dan Sukidin. Metode Penelitian Kuantitatif. 1 ed. Surabaya: Insan Cendekia, 2002.

Budiartinmgsih, Rahmita, Yusni Maulida, dan Taryono. "Faktor-Faktor Yang Mempengaruhi Peningkatan Pendapatan Keluarga Petani Melalui Sektor Informal Di Desa Kedaburapat, Kecamatan Rangsang Barat, Kabupaten Bengkalis.” Jurnal 
Ekonomi 18, no. 1 (Maret 2010): 79-93. Diakses 12 Juli 2019.

https://ejournal.unri.ac.id/index.php/JE/article/view/748.

Burkett, Larry. Bisnis Menurut Alkitab. 1 ed. Yogyakarta: Yayasan ANDI, 1997.

Darmaputera, Eka. Iman: Menjawab Pertanyaan, Mempertanyakan Jawaban. 6 ed.

Jakarta: BPK Gunung Mulia, 2011.

Darwanto. "Peran Entrepreneurship Dalam Mendorong Pertumbuhan Ekonomi Dan

Peningkatan Kesejahteraan Masyarakat.” OneSearch 1, no. 1 (2012): 11-24.

Diakses 18 Februari 2019.

https://onesearch.id/Record/IOS2852.36859?widget=1\&repository_id=2731.

Dekker, Peter. Entrepreneirship, Bisnis Sebagai Sebuah Misi. Makassar: Sekolah Tinggi

Theologia Jaffray, 2019.

"Entrepreneurship and the Relation with Mission in the Church of

Indonesia" Jurnal Jaffray [Online], Volume 18 Number 2 (27 October 2020), 177-

198. https://ojs.sttjaffray.ac.id/JJV71/article/view/437.

Dewanti, Ratih, dan Ginda Sihombing. "Analisis Pendapatan Usaha Peternakan Ayam

Buras (Studi Kasus di Kecamatan Tegalombo, Kabupaten Pacitan).” Buletin

Peternakan 36, no. 1 (Februari 2012): 48-56. Diakses 10 Juli 2019. https://journal.ugm.ac.id/buletinpeternakan/article/view/1276.

Djadi, Jermia. "Peranan Pemuda Gereja Dalam Pembangunan Bangsa." Jurnal Jaffray 3, no. 1 (2005): 41-46. Diakses 12 Juni 2019.

https://ojs.sttjaffray.ac.id/index.php/JJV71/article/view/142/pdf_103.

Dwiyanisa, Ashila. "Dukungan bandung Creative City Forum Terhadap Rintisan Usaha

Baru Generasi Muda Kota Bandung." Jurnal Ekonomi, Bisnis \& Entrepreneurship 11, no. 2 (Oktober 2017): 113-122. Diakses 25 Juli 2019.

http://jurnal.stiepas.ac.id/index.php/jebe/article/view/203.

Fatkhurahman. "Kepuasan Berwirausaha Melalui Kemauan Untuk Berkarya Usaha

Industri Kecil”, Jurnal Ekonomi dan Bisnis Islam 1, No. 2 (Desember 2016): 146170. Diakses 21 Mei 2019.

http://www.oalib.com/paper/5280415\#.XWOmjCMzbIU

Florida W. M. Hutabarat, Ruth. "Strategi Pengembangan Usaha Kuliner di Kota Malang

Berbasis Ekonomi Kreatif.” JESP 7, no. 1 (2015): 12-20. Diakses 04 Juli 2019.

journal.um.ac.id/index.php/jesp/article/view/5312.

Frinces, Heflin Z. "Pentingnya Profesi Wirausaha di Indonesia." Jurnal Ekonomi Dan

Pendidikan 7, no. 1 (2010): 34-57. Diakses 21 Juli 2019.

https://journal.uny.ac.id/index.php/jep/article/view/576.

Furqon, Danang Faizal. "Pengaruh Modal Usaha, Lama Usaha, dan Sikap Kewirausahaan

Secara Bersama-sama Terhadap Pendapatan Pengusaha Lanting. Di Desa Lemah

Duwur, Kecamatan Kuwarasan, Kabupaten Kebumen.” Jurnal Pendidikan dan

Ekonomi 7, no. 7 (2018): 51-59. Diakses 13 Juli 2019.

http://journal.student.uny.ac.id/ojs/index.php/ekonomi/article/view/8884.

GKII Syalom. Keputusan Rapat Kerja Pengurus. Makassar: 2018.

Gunawijaya, Rahmat. "Kebutuhan Manusia Dalam Pandangan Ekonomi Kapitalis dan

Ekonomi Islam.” Al-Maslahah 13, no. 1 (2017): 131-150. Diakses 09 Mei 2019.

https://jurnaliainpontianak.or.id/index.php/Almaslahah/article/view/921.

Hall, David W., dan Matthew D. Burton. Calvin dan Perdagangan. 1 ed. Surabaya: Momentum, 2015.

Hasanah. Membangun Jiwa Entrepreneur Anak Melalui Pendidikan Kejuruan. 1 ed.

Makassar: CV. Misvel Aini Jaya, 2015. Diakses 12 Mei 2019.

http://eprints.unm.ac.id/1808/2/BUKU\%20REFERENSI-HASANAHx.pdf. 
Hasmawaty. "Kemampuan Menyimak Anak Melalui Kegiatan Bercerita (Studi Kasus Pada Taman Penitipan Anak Athirah Makassar)." Jurnal Ilmu Teologi dan Pendidikan Agama Kristen 1, no. 1 (Juni 2020): 55-68. https://ojs.sttjaffray.ac.id/jitpk/article/view/463.

Ismail, Andar. Selamat Berkarya. Jakarta: BPK Gunung Mulia, 2000. - Selamat Sejahtera. Jakarta: BPK Gunung Mulia, 2002.

Januar Ristanti, Astrianditya, dan Fereshti Nurdiana Dihan. "Pengaruh Kualitas Kehidupan Kerja dan Kepuasan Kerja Terhadap Kinerja Karyawan PT Pertamina Persero RU IV Cilacap.” Jurnal Akuntansi dan Pendidikan 5, no. 1 (April 2016): 53-64. Diakses 11 Juli 2019. http://ejournal.unipma.ac.id/index.php/assets/article/view/1187.

“Kamus Besar Bahasa Indonesia (KBBI) Online.” Diakses 2 Mei 2019. https://kbbi.web.id/.

"Kredit Usaha Rakyat." Kementerian Koordinator Bidang Perekonomian Republik Indonesia, 2019. http://www.kur.ekon.go.id/.

Kuyper, Abraham. Iman Kristen dan Problema Sosial. Surabaya: Momentum, 2004.

Latifa, Nurul, Rosmala Dewi, dan Fitriana. "Peran Wirausaha Perempuan Dalam Meningkatkan Kesejahteraan Keluarga (Studi Kasus Usaha Penjahit Perempuan di Mukim Lhoknga)." Jurnal Ilmiah Mahasiswa Pendidikan Kesejahteraan Keluarga 3, no. 2 (Mei 2018): 65-72. Diakses 15 Juli 2019. http://www.jim.unsyiah.ac.id/pkk/article/view/9731/0.

Lazuardi, Mandra, dan Mochamad Sandy Triady. Ekonomi Kreatif: Rencana Pengembangan Kuliner Nasional 2015-2019. 1 ed. Jakarta: Republik Solusi, 2015. Diakses 04 Juli 2019. http://indonesiakreatif.bekraf.go.id/ikpro/wpcontent/uploads/2015/07/Rencana-Pengembangan-Kuliner-Nasional.pdf.

Magany, Vesto Proklamanto. "SR XVI PGI: Pemberdayaan Ekonomi Jemaat Tak Lagi Bicara Teori.” PGI, Oktober 2014. Diakses 2 Mei 2019. https://pgi.or.id/sr-xvi-pgipemberdayaan-ekonomi-jemaat-tak-lagi-bicara-teori/.

Manullang, Maria Cristina. "Penghargaan dan Kondisi Pekerjaan Mempengaruhi Kualitas Hidup Profesional Perawat" Hospitalia, 1 no. 1 (Februari 2018): 51-66. Diakses 20 Agustus 2019. https://www.esaunggul.ac.id/penghargaan-dan-kondisi-pekerjaanmempengaruhi-kualitas-hidup-profesional-perawat/

Manullang, Sudianto. "Konsep Misi-Diakonia Untuk Konteks Indonesia.” Stulos 16, no. 1 (2018): 28-46. Diakses 19 Januari 2019.

http://sttaletheia.ac.id/perpustakaan/index.php?p=show_detail\&id=31785.

Mardiana, Irma, dan Nurafni R. Rubiyanti. "Analisis Kepuasan Pelanggan Berdasarkan Dimensi Servquoal Menggunakan Metode Importance Performance Analysis." Jurnal Ekonomi, Bisnis \& Entrepreneurship 11, no. 1 (April 2017): 47-58. Diakses 19 Mei 2019. http://jurnal.stiepas.ac.id/index.php/jebe/article/view/173.

Mariatun, Baiq, dan Muhammad Arief Rizka. "Pemberdayaan Masyarakat Berbasis Agropreneur dalam Mengatasi Pengangguran di Desa Gerupuk Kabupaten Lombok Tengah.” Jurnal Kependidikan 5, no. 1 (2019): 8-15. Diakses 13 Mei 2019. http://ojs.ikipmataram.ac.id/index.php/jurnalkependidikan/article/view/1387/1110.

Mega Karinda, Jantje L. Sepang, Christoffel M. O. Mintardjo "Kajian Terhadap Pelatihan dan Pengembangan Karyawan dalam Peningkatan Kinerja Pelayanan di Bank SulutGo cabang Manado" Jurnal Berkala Ilmiah Efisiensi 16, no. 3 (2016): 382393. Diakses 07 Agustus 2019. https://ejournal.unsrat.ac.id/index.php/jbie/article/view/13423. 
“Menyulut Spirit Entreprenuership Warga Gereja.” PGI, Agustus 2017. Diakses 21 Mei 2019. https://pgi.or.id/menyulut-spirit-entreprenuership-warga-gereja/.

Munira, Sitti, La Ode Nafiu, dan Andi Murlina Tasse. "Performans Ayam Kampung Super Pada Pakan Yang Disubstitusi Dedak Padi Fermentasi, Dengan Ferformator Berbeda." Jitro 3, no. 2 (2016): 21-29. Diakses 10 Juli 2019. http://ojs.uho.ac.id/index.php/peternakan-tropis/article/view/1683/1210.

Muslihatunnisa, Jaziela. "Dampak Keberadaan Minimarket Franchise Terhadapa Usaha Pedagang Kelontong Di Kecamatan Pacitan , Kabupaten Pacitan, Jawa Timur.” Jurnal Bumi Indonesia 4, no. 2 (2015): 1-10. Diakses 05 Juli 2019. http://lib.geo.ugm.ac.id/ojs/index.php/jbi/article/view/310.

Nababan, Togam Sihol. "Gereja dan Kesejahteraan Warga Dalam Perspektif Ekonomi Kerakyatan.” SSRN, (2011): 1-10. Diakses 13 Juni 2019. https://papers.ssrn.com/sol3/papers.cfm?abstract_id=2310489.

Nanuru, Ricardo F. dan Lomas Beatris Limpong. "Pandangan Gereja Masehi Injili di Halmahera (GMIH) Wilayah Pelayanan Tobelo Terhadap Dunia Bisnis.” Jurnal Uniera 3, no. 1 (2014): 51-60. Diakses 01 Mei 2019. https://osf.io/preprints/hz8cq/.

Nikijuluw, Victor P.H. Kitab Amos: Tanggung Jawab Orang Kristen dalam Mengatasi Masalah Sosial, Budaya, Ekonomi dan Politik. Bogor: Literatur Perkantas, 2016.

Nurseto, Tejo. "Strategi Menumbuhkan Wirausaha Kecil Menengah yang Tangguh." Jurnal Ekonomi \& Pendidikan 1, no.1 (Februari 2004): 96-105. Diakses 21 Juli 2019. https://journal.uny.ac.id/index.php/jep/article/view/675.

Oiladang, Chris S. Bekerja Selagi Hari Siang. Kupang: Desna Life Ministry, 2016.

Palabiran, Berniaty, dan Daniel Ronda. "Pandangan Alkitab Tentang Praktik Bisnis Di Kalangan Hamba Tuhan Penuh Waktu." Jurnal Jaffray 8, no. 2 (Oktober 2010): 35-47. Diakses 07 April 2019.

https://ojs.sttjaffray.ac.id/index.php/JJV71/article/download/45/pdf_40.

Pasande, Purnama, dan Ezra Tari. "Peran Gereja Dalam Mengembangkan Program Kewirausahaan Dalam Menghadapi Era Digital" Visio Dei 1, no. 1 (Juli 2019): 3858. Diakses 13 Juli 2019. http://jurnal.sttstarslub.ac.id/index.php/js/article/view/6.

Pramono, Catur. "Penyuluhan Kampuh dan Kekuatan Las Untuk Pemuda Desa Gulon." Civitas Ministerium 1, no. 1 (Oktober 2017): 21-28. Diakses 17 Juli 2019. http://jurnal.untidar.ac.id/index.php/civitasministerium/article/view/570.

Purnomo, Bambang Raditya. "Efektivitas Pelatihan Kewirausahaan dalam Meningkatkan Motivasi Berwirausaha pada Individu Penyandang Tuna Rungu" Ekspektra 1, no 1 (Februari 2017): 21-30. Diakses 02 Agustus 2019. https://ejournal.unitomo.ac.id/index.php/manajemen/article/view/85

Purnomo, Margo. "Perspektif Definisi Entrepreneurship." ReseacrhGate 1, no. 2 (2010): 66-81. Diakses 27 Mei 2019. https://www.researchgate.net/search?q=PERSFEKTIF\%20DEFINISI\%20ENTREP RENEURSHIP.

Purwanto, Edi. "Meneropong Ketimpangan Sosial Ekonomi Masyarakat Yahudi Pada Zaman Yesus Melalui Lensa Teori Sosial.” Stulos 17, no. 1 (2019): 94-119. Diakses 17 Juni 2019. http://www.sttb.ac.id/akademik/88-saranaprasarana/download/stulos/2013/April/Stulos-V.12-No.-1-April-2013-06FORMASI-SPIRITUAL-HOLISTIK-DI-SEKOLAH-TEOLOGI.pdf.

Puspitasari, Dewi Cahyani. "Menjadi Sociopreneur Muda: Potret dan Dinamika Momsociopreneur." Jurnal Studi Pemuda 7, no. 2 (2018): 76-89. Diakses 06 Mei 2019. https://jurnal.ugm.ac.id/jurnalpemuda/article/view/40524/23826. 
Puspitawati, Herien. "Ketahanan dan Kesejahteraan Keluarga.” Departemen Ilmu Keluarga dan Konsumen (2013): 1-18. Diakses 06 Juli 2019.

https://herienpuspitawati.files.wordpress.com/2015/05/3a-2015-kesejahteraan-danketahanan-keluarga-rev.pdf.

Qolik, Abdul, Yoto Basuki, Sunomo, dan Wahono. "Bahaya Asap dan Radiasi Sinar Las Terhadap Pekerja Las di Sektor Informal.” Jurnal Teknik Mesin Dan Pembelajaran 1, no. 1 (Juni 2018): 1-4. Diakses 17 Juli 2019. http://journal2.um.ac.id/index.php/jtmp/article/view/6098.

Rahman, Fadly. "Kuliner sebagai Identitas Keindonesiaan." Jurnal Sejarah 21, no. 1 (Januari 2018): 43-63. Diakses 13 Juli 2019.

http://jurnal.masyarakatsejarawan.or.id/index.php/js/article/download/118/95/.

Rainiyati, Ahmad Riduan, dan Sarah Fiebrina Heraningsih. "Program Pengembangan Kewirausahaan (PPK) Usaha Tanaman Herbal Mahasiswa Fakultas Pertanian Universitas Jambi.” Jurnal Abdimas Unmer Malang 3, no. 1 (2018): 1-5. Diakses 13 Juli 2019. http://jurnal.unmer.ac.id/index.php/jpkm/article/download/2507/1640.

Rusno. "Dampak Pesatnya Minimarket Waralaba Terhadap Usaha Kecil (Jenis Ritel)." Jurnal Ekonomi Modernisasi 4, no. 3 (2008): 194-207. Diakses 05 Juli 2019. http://ejournal.unikama.ac.id/index.php/JEKO/article/view/235.

Sabdono, Erastus. Biblical Entrepreneurship. 1 ed. Jakarta: Rehobot Literatur, 2015.

Safitri, Irvina, Darmawan Salman, dan Rahmadanih. "Strategi Pengembangan Usaha Kuliner: Studi Kasus Warung Lemang di Jeneponto, Sulawesi Selatan.” JSEP 14, no. 2 (2018): 183-194. Diakses 09 Juli 2019. http://journal.unhas.ac.id/index.php/jsep/article/view/4620/pdf.

Sapir, Heri Pratikto, Wasiti Wasiti, dan Agus Hermawan. "Model Pembelajaran Kewirausahaan Berbasis Kearifan Lokal Untuk Penguatan Ekonomi." Jurnal Pendidikan dan Pembelajaran 21, no. 1 (2014): 79-91. Diakses 11 Mei 2019. http://journal.um.ac.id/index.php/pendidikan-dan-pembelajaran/article/view/4524.

Satria Alam, Faris. "Pengguna Jasa Angkutan Umum Jenis Angkot Di Jakarta Dalam Perspektif Hukum Perlindungan Konsumen." Salam 3, no. 2 (2016): 197-216. Diakses 25 Juli 2019. http://journal.uinjkt.ac.id/index.php/salam/article/view/7857.

Serli dan Hengki Wijaya. "Metode Permainan dalam meningkatkan Pemahaman Firman Tuhan pada Remaja GKII Okahapi Sumba Timur.” Jurnal Ilmu Teologi dan Pendidikan Agama Kristen 1, no. 1 (Juni 2020): 17-28. http://dx.doi.org/10.25278/jitpk.v1i1.459.

Setio, Robert. Teologi Ekonomi. 1 ed. Jakarta: BPK Gunung Mulia, 2002.

Slamet, Franky, Kurnia Hetty Tunjungsari, dan Le Mei. Dasar-Dasar Kewirausahaan Teori dan Praktek. 1 ed. Jakarta: Indeks, 2016.

Sin, Sia Kok. "Kepedulian Sosial Dalam Kitab Keluaran.” Jurnal Theologi Aletheia 16, no. 7 (September 2014): 1-18. Diakses 05 April 2019. http://sttaletheia.ac.id/wpcontent/uploads/2014/10/Jurnal-Vol-16-no-7-September-2014.pdf.

Simon, Julianto. "Kewirausahaan Jemaat: Sebuah Alternatif Berteologi." Waskita 3, no. 1 (2016). http://ejournal.uksw.edu/waskita/article/view/1309.

Sodiq, Akhmad, Farida Rizki Fauziyah, Yusmi Nur Wakhidati, Pambudi Yuwono, dan Suwarno Suwarno. "Sistem Produksi Peternakan Sapi Potong di Pedesaan dan Strategi Pengembangannya." Agripet 17, no. 1 (2017): 60-66. Diakses 12 Juni 2019. http://jurnal.unsyiah.ac.id/agripet/article/download/7643/6563.

Stamps, Donald C. Alkitab Penuntun Hidup Berkelimpahan. Malang: Gandum Mas, 1994. Stott, John. Isu-isu Global Menentang Kepemimpinan Kristiani. 1 ed. Jakarta: Yayasan Komunikasi Bina Kasih, 2012. 
Subagyo, Andreas B. Pengantar Riset Kuantitatif Dan Kualitatif. 1 ed. Bandung: Kalam Hidup, 2004.

Subkhie, Hasan, Amiruddin Saleh, dan Suryahadi Suryahadi. “Analisis Kelayakan Usaha Peternakan Ayam Pedaging dengan Pola Kemitraan di Kecamatan Ciampea Kabupaten Bogor.” Jurnal Manajemen Pengembangan Industri Kecil Menengah 7, no. 1 (2012): 54-63. Diakses 10 Juli 2019.

http://journal.ipb.ac.id/index.php/jurnalmpi/article/view/4872.

Sumanto, Teori dan Aplikasi Metode Penelitian, 1 ed. Jakarta: CAPS, 2014.

Sumbung, Grace, Agus Suman, Kliwon Hidayat, dan Paulus Kindangen. "Peran Gereja Dalam Peningkatan Ekonomi Masyarakat Di Tomohon Sulawesi Utara." Wacana 15, no. 4 (2012): 8-14. Diakses 01 Juli 2019. https://wacana.ub.ac.id/index.php/wacana/article/view/264.

Supriyatno, Dadang, dan Ari Widayanti. "Kinerja Layanan Bis Kota di Kota Surabaya." Jurnal Transportasi 10, no. 1 (April 2010): 43-52. Diakses 19 Juli 2019. http://journal.unpar.ac.id/index.php/journaltransportasi/article/view/374.

Suryanto, Agus, Noor Hudallah, dan Riana Defi Mahadji Putri. “Kelompok Usaha Las Listrik dengan Teknik Desain Dengan Teknik Desain Ornamen Teralis Pagar Berbasis Komputer." Rekayasa 15, no. 1 (Juli 2017): 2-10. Diakses 17 Juli 2019. https://journal.unnes.ac.id/nju/index.php/rekayasa/article/view/12560.

Susanti, Nanik. "Perancangan e-marketing Bagi UMKM Pengrajin Tas." Jurnal Simetris 9, no. 1 (April 2018): 717-722. Diakses 12 Juli 2019.

https://jurnal.umk.ac.id/index.php/simet/article/view/2042.

Suswakara, Ignasius. "Menjadi Pewarta Tuhan Bercermin dari ST. Paulus," Jurnal Atma Reksa 2, no.2 (2017): 1-7. Diakses 18 Agustus 2019. http://jurnal.stiparende.ac.id/index.php/jar/article/download/1/1

Syarifah, Lailatis. “Teori Dasar Ekonomi Mikro dalam Literatur Islam Klasik.” EkBis Jurnal Ekonomi dan Bisnis 1, no. 1 (2017): 74-100. Diakses 12 Mei 2019. http://ejournal.uin-suka.ac.id/febi/ekbis/article/download/11-05/557.

Syarifuddin, Didin, Chairil M. Noor, dan Acep Rohendi. "Memaknai Kuliner Lokal Sebagai Daya Tarik Wisata Kota Bandung.” Jurnal Abdimas 1, no.1 (2018): 55-64. Diakses 09 Juli 2019. https://ejournal.bsi.ac.id/ejurnal/index.php/abdimas/article/view/2866/1859.

Teddy Kusnandar, Yotam. "Kajian Teologis Tentang Kode Etik Pelayanan Gerejawi." Jurnal Antusias 5, no. 1 (Juni 2017): 83-100. Diakses 05 Juli 2019. http://sttintheos.ac.id/e-journal/index.php/antusias/article/view/157/125.

Tri Iriyanto, Maleo. "Peranan industri kerajinan kulit terhadap pendapatan rumah tangga pengrajin di Dusun Manding Desa Sabdodadi Kecamatan Bantul Kabupaten Bantul." Jurnal Pendidikan dan Ekonomi 6, no. 6 (2017): 552-564. Diakses 05 Juli 2019. http://journal.student.uny.ac.id/ojs/index.php/ekonomi/article/view/7232.

Tsukahira, Peter. My Father's Business. 2 ed. Jakarta: Metanoia Publishing, 2005.

Tulusan, Femy M. G., dan Very Y. Londa. "Peningkatan Pendapatan Masyarakat Melalui Program Pemberdayaan Di desa Lolah II Kecamatan Tombariri Kabupaten Minahasa." Jurnal LPPM Bidang EkoSosBudKum 1, no. 1 (2014): 92-105. Diakses 15 April 2019.

https://ejournal.unsrat.ac.id/index.php/lppmekososbudkum/article/view/7215.

“Usaha Mikro Kecil.” Badan Pusat Statistik. Diakses 20 Maret 2019. https://www.bps.go.id/subject/35/usaha-mikro-kecil.html.

Veen, Made Gunaraksawati Mastra-Ten. Teologi Kewirausahaan. 1 ed. Yogyakarta: Taman Pustaka Kristen, 2009. 
Wadhan. "Konsepsi semangat kewirausahaan Ciputra." STAIN Pamekasan 13, no. 1 (2016): 179-204. Diakses 01 Agustus 2019.

http://ejournal.stainpamekasan.ac.id/index.php/nuansa/article/view/884/752.

Wazin. "Karakteristik Ekonomi Rumah Tangga Dan Relevansinya Dengan Konsep Ekonomi Syariah." UIN Sultan Maulana Hasanuddin Banten 35, no. 1 (2018): 1836. Diakses 09 Mei 2019.

http://jurnal.uinbanten.ac.id/index.php/alqalam/article/download/1179/941/.

Widiansyah, Apriyanti. "Peran Ekonomi dalam Pendidikan dan Pendidikan dalam Pembangunan Ekonomi." Cakrawala 17, no. 2 (September 2017): 207-215. Diakses 04 Agustus 2019.

http://ejournal.bsi.ac.id/ejurnal/index.php/cakrawala/article/download/2612/1797.

Widodo. "Model Pengembangan Kepuasan Kerja Dengan Kepuasan Keluarga." Jurnal Bisnis dan Ekonomi 17, no. 1 (Maret 2010): 61-73. Diakses 20 Juli 2019. https://www.unisbank.ac.id/ojs/index.php/fe3/article/view/326.

Widyatmadja, Yosep P. Diakonia Sebagai Misi Gereja. Yogyakarta: Kanisius, 2009.

Wijaya, Hengki. Analisis Data Kualitatif Ilmu Pendidikan Teologi. 1 ed. Makassar: Sekolah Tinggi Theologia Jaffray, 2018.

—. Metodologi Penelitian Pendidikan Teologi. Makassar: Sekolah Tinggi Theologia Jaffray, 2016.

Wijaya, Hengki, Reinaldy Hank Rouw, dan A. R. Kadir. "Brassica Box Food Products as a Healthy Local Food Innovation in the Covid-19 Pandemic Period." IOP Science 575 (2020): 1-8. https://iopscience.iop.org/article/10.1088/17551315/575/1/012011/pdf.

Wijaya, Yahya. Kesalehan Pasar - Kajian Teologis Terhadap Isu-isu Ekonomi dan Bisnis di Indonedia. 1 ed. Jakarta: Grafika Kreasindo, 2010.

Winardi. Kamus Ekonomi (Inggris-Indonesia). Bandung: Alumni, 1982.

Winardi, J. Entrepreneur dan Entrepreneurship. 1 ed. Jakarta: Prenadamedia Group, 2003. 